\title{
Aminoácidos Digestíveis Verdadeiros do Milheto, do Milho e Subprodutos do Milho, Determinados com Galos Adultos Cecectomizados ${ }^{1}$
}

\author{
Paulo Borges Rodrigues ${ }^{2}$, Horacio Santiago Rostagno ${ }^{3}$, Luiz Fernando Teixeira Albino ${ }^{3}$, \\ Paulo Cezar Gomes ${ }^{3}$, Walter Amaral Barboza ${ }^{4}$, Ricardo Vianna Nunes ${ }^{5}$
}

\begin{abstract}
RESUMO - Os coeficientes de digestibilidade e o conteúdo de aminoácidos digestíveis verdadeiros do milho e seus subprodutos e do milheto foram determinados utilizando-se galos cecectomizados, em que 11 alimentos testados foram fornecidos a seis galos ( $15 \mathrm{~g}$ pela manhã e $15 \mathrm{~g}$ à tarde, após jejum de 24 horas) e seis galos foram mantidos em jejum para determinação das perdas endógenas. Após obtidos os coeficientes de digestibilidade e calculados os aminoácidos digestíveis, ajustaram-se equações para predizer a composição do milho e seus subprodutos em lisina (LIS), metionina (MET), metionina + cistina $(\mathrm{M}+\mathrm{C})$, treonina (TRE) e arginina (ARG), totais e digestíveis, em função da composição em proteína bruta (PB), fibra bruta (FB), extrato etéreo (EE) e matéria mineral (MM). Os coeficientes médios de digestibilidade dos aminoácidos (essenciais e não-essenciais) das amostras de milho 1, 2, Quality Protein Maize (QPM) e pré-cozido, farelos de glúten 60 e 21, gérmen de milho, gérmens de milho fino e desengordurado e dos milhetos 1 e 2 foram 92,02 e 90,69; 88,62 e 87,33;88,40 e 85,75; 90,20 e 88,99; 95,04 e 94,84; 82,11 e 79,10; 91,84 e 91,30; 92,56 e 91,59; 87,92 e 86,18; 91,04 e 88,70; 93,55 e 93,79\%, respectivamente. O milheto apresentou aminoácidos de alta digestibilidade, semelhante ao milho. As equações $\mathrm{LIS}=0,26488+0,01198 \mathrm{~PB} ; \mathrm{MET}=-0,01315+0,02031 \mathrm{~PB} ; \mathrm{M}+\mathrm{C}=0,07769+0,03448 \mathrm{~PB} ; \mathrm{TRE}=0,05576+0,03410 \mathrm{~PB}$ e $A R G=0,30805+0,02370 \mathrm{~PB}$ e LIS $=0,23518+0,01067 \mathrm{~PB} ; \mathrm{MET}=-0,02198+0,0195 \mathrm{~PB} ; \mathrm{M}+\mathrm{C}=0,04767+0,03143 \mathrm{~PB}$ $\mathrm{TRE}=-0,01738+0,03156 \mathrm{~PB}$ e $\mathrm{ARG}=0,28013+0,02318 \mathrm{~PB}$ podem predizer o conteúdo em aminoácidos totais e digestíveis, respectivamente, do milho e seus subprodutos.
\end{abstract}

Palavras-chave: aminoácidos digestíveis, galos cecectomizados, milheto, milho, equações de predição

\section{True Digestible Amino Acids of the Millet, Corn and Corn Byproducts, Determined with Cecectomized Adult Cockerels}

\begin{abstract}
S - The digestibility coefficients and the true digestible amino acids contents of corn and corn byproducts were determined by using cecectomized adult cockerels. Each one of the 11 feedstuffs evaluated was fed to six cockerels, consuming 15 g at $8 \mathrm{a} . \mathrm{m}$. and $15 \mathrm{~g}$ at 4 p.m. after fastening by 24 hours. Simultaneously, six cockerels were fasted to determine metabolic and endogenous losses. After determination of the digestibility coefficients and calculation of the digestible amino acids, prediction equations were simulated to predict the corn and corn byproducts composition in lysine (LYS), methionine (MET), methionine + cystine (Met + Cys), threonine (THR) and arginine (ARG), total and digestible, based on chemical composition (crude protein - CP, crude fiber - CF, ether extract - EE and ash). The amino acids digestibility coefficients means (essential and non-essential AA) of the corn samples (1 and 2), quality protein maize and pre-cooked corn, corn gluten meal, corn gluten feed, corn germ, fine corn germ and free-fat corn germ and of the millets ( 1 and 2 ) were 92.02 e $90.69 ; 88.62$ e $87.33 ; 88.40$ e $85.75 ; 90.20$ e $88.99 ; 95.04$ e $94.84 ; 82.11$ e 79.10; 91.84 e $91.30 ; 92.56$ e $91.59 ; 87.92$ e $86.18 ; 91.04$ e $88.70 ; 93.55$ e $93.79 \%$, respectively. The millet shown higher amino acids digestibility and was similar to corn. The equations LYS $=0.26488+0.01198 \mathrm{CP}$; $\mathrm{MET}=-0.01315+0.02031 \mathrm{~PB} ; \mathrm{Met}+\mathrm{Cys}=0.07769+0.03448 \mathrm{~PB} ; \mathrm{THR}=0.05576+0.03410 \mathrm{~PB}$ and $\mathrm{ARG}=0.30805$ $+0.02370 \mathrm{~PB}$ and LYS $=0.23518+0.01067 \mathrm{~PB} ; \mathrm{MET}=-0.02198+0.0195 \mathrm{~PB} ; \mathrm{Met}+\mathrm{Cys}=0.04767+0.03143 \mathrm{CP}$; THR $=-0.01738+0.03156 \mathrm{~PB}$ e $\mathrm{ARG}=0.28013+0.02318 \mathrm{~PB}$ should be used to predict the total and digestible amino acids contents, respectively, of the corn and corn byproducts.
\end{abstract}

Key Words: digestible amino acids, cecectomized cockerels, millet, corn, prediction equations

\footnotetext{
${ }_{1}^{1}$ Parte da tese de doutorado do primeiro autor - Projeto financiado pelo CNPq.

2 Professor do Departamento de Zootecnia da UFLA. E.mail: pborges@ufla.br

3 Professores do Departamento de Zootecnia da UFV. E.mail: rostagno@mail.ufv.br

${ }^{4}$ Professor do Departamento de Zootecnia da UFRPE.

${ }^{5}$ Aluno de doutorado do Departamento de Zootecnia da UFV.
} 


\section{Introdução}

$\mathrm{Na}$ formulação de uma dieta de custo mínimo, a composição dos ingredientes, a exigência animal e o custo são os três fatores considerados. Estas condições, no entanto, complicam-se quando se pretende considerar a absorção do nutriente (BELLAVER, 1994). Por outro lado, a crescente tendência mundial de elevação nos preços das fontes proteicas e a poluição ambiental por nitrogênio têm levado os nutricionistas a formular rações que atendam adequadamente às exigências nutricionais, mesmo quando se utilizam alimentos alternativos, em função do valor nutritivo, do custo e da oferta desses produtos (ALBINO e SILVA, 1996).

O milho, por sua vez, apesar de ser uma fonte energética nas formulações, contribui com boa parte da proteína dietética, sendo responsável por aproximadamente 25 e $33 \%$ da proteína bruta total, respectivamente, nas rações de frangos e poedeiras (BERTECHINI et al., 1999). Nesse sentido, o conhecimento da digestibilidade dos aminoácidos, tanto do milho como de outros alimentos, é particularmente importante na formulação de rações, uma vez que permite a utilização de variados ingredientes, como os subprodutos industriais e alimentos alternativos, dispensando a utilização de margem de segurança, que muitas vezes não é suficiente para garantir máximo desempenho (ALBINO e SILVA, 1996).

Dessa forma, o interesse pela digestibilidade ou disponibilidade dos aminoácidos cresceu nos últimos anos, sendo bem conhecida a importância de se considerar a digestibilidade nas formulações. Sabese também que as quantidades de aminoácidos digestíveis, na maioria dos alimentos, são substancialmente menores que a total e, associado a isto, o desenvolvimento de ensaios de digestibilidade mais rápidos, bem como o aperfeiçoamento daqueles já existentes, tornou possível a condução de mais pesquisas relacionadas ao assunto (PARSONS, 1996).

A possibilidade de se utilizarem equações que possam predizer o conteúdo de aminoácidos dos alimentos, em função da composição química, também é uma ferramenta que pode ser útil para os nutricionistas. Os NRC (1994 e 1998) apresentam uma série de equações lineares que podem ser utilizadas para estimar o conteúdo de aminoácidos dos alimentos, em função da proteína bruta, e também equações que possibilitam estimar os aminoácidos a partir da composição proximal. Trabalhos para predi- zer o conteúdo de aminoácidos digestíveis, em função da composição química dos alimentos, no entanto, são escassos.

O objetivo deste trabalho foi determinar os coeficientes de digestibilidade e o conteúdo em aminoácidos digestíveis verdadeiros do milheto, do milho e de seus subprodutos e, a partir dos resultados experimentais obtidos, estabelecer equações para predizer a composição dos alimentos em alguns aminoácidos totais e digestíveis do milho e de subprodutos, em função da composição em proteína bruta (PB), fibra bruta (FB), extrato etéreo (EE) e matéria mineral (MM) dos alimentos.

\section{Material e Métodos}

Para determinação dos coeficientes de digestibilidade verdadeira dos aminoácidos e do conteúdo de aminoácidos digestíveis verdadeiros do milheto, do milho e de seus subprodutos, foi conduzido um ensaio biológico no Laboratório Animal do DZO/ UFV. Utilizaram-se a adaptação do método de alimentação forçada, também conhecido como alimentação precisa (SIBBALD, 1979), e galos Leghorne adultos cecectomizados, com 21 meses de idade e peso médio de $2132 \pm 257 \mathrm{~g}$. Os galos foram cecectomizados no setor de avicultura do DZO/UFV, por meio de laparotomia abdominal e anestesia local, conforme a metodologia descrita posteriormente por PUPA et al. (1998). As temperaturas, mínima e máxima, médias registradas no período experimental foram $22,9 \pm 1,1^{\circ} \mathrm{C}$ e $28,9 \pm 3,1^{\circ} \mathrm{C}$, respectivamente.

Foram testados 11 alimentos, sendo três amostras de milho (milhos 1, 2 e QPM - Quality Protein Maize), milho pré-cozido, farelo de glúten 60 , farelo de glúten 21, gérmen de milho, gérmen de milho fino, gérmen de milho desengordurado e duas amostras de milheto (milhetos 1 e 2). O milho QPM representa uma variedade de milho originalmente desenvolvida pelo Centro Internacional de Melhoramento de Milho e Trigo, no México, melhorada em suas qualidades agronômicas e de composição em aminoácidos pelo Centro Nacional de Pesquisas em Milho e Sorgo (CNPMS - EMBRAPA) de Sete Lagoas/Minas Gerais. A variedade foi melhorada para conter $50 \%$ a mais de lisina, em relação ao milho comum. O milho pré-cozido é o produto obtido do grão de milho moído, extrusado a vapor (pré-cozimento a $85-90^{\circ} \mathrm{C}$ ), passando posteriormente por um processo de secagem, novamente moído e destinado à alimentação animal

Rev. bras. zootec., 30(6S):2046-2058, 2001 
(SIMILHO Indústria e Comércio de Milho Guimarães LTDA - Uberlândia/Minas Gerais).

Cada um dos 11 alimentos foi fornecido a seis galos, repetidos três vezes no tempo, sendo um galo por unidade experimental, observando-se que cada galo não deveria receber o mesmo alimento duas vezes. As excretas das duas repetições que receberam o mesmo alimento foram coletadas em um mesmo vidro, totalizando assim três repetições de dois galos por alimento. Simultaneamente, foram mantidas em jejum três repetições de dois galos, para determinação das perdas endógenas e metabólicas. Utilizou-se um intervalo de quatro dias entre cada repetição, para descanso dos galos, período no qual as aves receberam uma ração para frangos de corte em terminação, objetivando melhor recuperação. Antes do período experimental, os galos foram alojados nas baterias e passaram por um período de adaptação, recebendo alimentação em dois turnos de 1 hora, às 8 e 16 h, visando à dilatação do papo. Em seguida, foram mantidos em jejum por 24 horas, com o objetivo de esvaziar o trato digestivo, e, então, forçados a ingerir $30 \mathrm{~g}$ do alimento teste, por meio de um funil-sonda introduzido via esôfago até o papo. Foram fornecidos $15 \mathrm{~g}$ dos alimentos às $8 \mathrm{~h}$ e $15 \mathrm{~g}$ às $16 \mathrm{~h}$, para evitar regurgitações. As bandejas sob o piso das gaiolas foram revestidas com plástico, e a coleta de excretas realizada às 8 e $16 \mathrm{~h}$, por um período de 56 horas, após iniciado o fornecimento dos alimentos. As excretas foram coletadas e acondicionadas em freezer até o final do experimento, quando foram descongeladas, devidamente quantificadas, homogeneizadas e secas em estufa de ventilação forçada a $55^{\circ} \mathrm{C}$, por um período de 72 horas. Posteriormente, as amostras dos alimentos foram analisadas em matéria seca e nitrogênio, por meio das metodologias descritas por SILVA (1990), e o conteúdo em aminoácidos, determinado no Laboratório da Eurolysine (Amiens França). Uma vez conhecida a quantidade de aminoácidos ingeridos e excretados, bem como a fração endógena determinada com os galos em jejum, determinaram-se os coeficientes de digestibilidade verdadeira de cada aminoácido (CDVaa), por intermédio da fórmula proposta por ROSTAGNO E FEATHERSTON (1977), a qual é apresentada a seguir, e posteriormente foi calculado o conteúdo de aminoácidos digestíveis verdadeiros de cada alimento. Os coeficientes de digestibilidade de cada aminoácido dos alimentos foram submetidos à análise estatística e aqueles cuja análise de variância apresentou efeito significativo $(\mathrm{P}<0,05)$, comparados pelo teste de agrupamento de Scott-Knott, sendo o procedimento estatístico realizado por meio do pacote SAEG - Sistema para Análises Estatísticas, versão 5.0 (UFV, 1992).

CDVaa =aminoácido(aa)ingerido-aa excretado + aa da fração endógena aminoácido ingerido(em gramas)

Uma vez determinados os coeficientes de digestibilidade dos aminoácidos e calculado o conteúdo de aminoácidos digestíveis verdadeiros, foram estimadas equações para predizer a composição em alguns aminoácidos totais e digestíveis (lisina, metionina, metionina + cistina, treonina, arginina) do milho e de subprodutos, por meio de regressões lineares simples e múltiplas, pelo Método de Eliminação Indireta ou Backward, utilizando-se o pacote SAEG, mencionado anteriormente. Utilizaram-se, na predição das equações, os valores de $\mathrm{PB}, \mathrm{FB}, \mathrm{EE}$ e MM. Para obter equações de maior precisão, foi adotado o teste t e significância de 5\% de probabilidade para cada variável componente do modelo, sendo consideradas somente as equações em que todas as variáveis independentes apresentassem significância no modelo.

\section{Resultados e Discussão}

A composição dos alimentos em aminoácidos essenciais totais está apresentada na Tabela 1 e a dos aminoácidos não-essenciais, na Tabela 2. Nota-se que as amostras de milho, em média, apresentaram ligeira variabilidade em relação aos valores descritos por ROSTAGNO et al. (1983); ALBINO et al. (1992); EMBRAPA (1991); PUPA (1995) e FISCHER JR. et al. (1998). No entanto, é possível observar que a variação foi maior, quando se compararam estes valores com os descritos no NRC (1994 e 1998) e aqueles apresentados por DALE (1999), logicamente devido às diferenças nas condições de solo, cultivo, clima e variedades, que podem resultar em diferenças na composição dos alimentos (BATH et al., 1999).

Entre as amostras de milho estudadas, o QPM foi o que apresentou maiores diferenças, com teor de lisina mais elevado, quando comparado à média das demais amostras $(32,0 \%)$. Isto era de se esperar, uma vez que esta variedade foi melhorada para conter um maior teor de lisina. Os valores do QPM determinados para lisina e treonina no presente experimento foram semelhantes àqueles relatados por

Rev. bras. zootec., 30(6S):2046-2058, 2001 
Tabela 1 - Conteúdo de aminoácidos essenciais totais do milho e subprodutos e do milheto

Table 1 - Total essential amino acids content of the corn and byproducts and of the millet

\begin{tabular}{|c|c|c|c|c|c|c|c|c|c|c|c|c|}
\hline \multirow[b]{2}{*}{$\begin{array}{l}\text { Alimento } \\
\text { Feedstuff }\end{array}$} & \multicolumn{12}{|c|}{$\begin{array}{c}\text { Aminoácidos } 1,2 \\
\text { Amino acids }\end{array}$} \\
\hline & $\begin{array}{l}\text { MS } \\
D M \\
(\%)\end{array}$ & $\begin{array}{l}\mathrm{PB} \\
C P \\
(\%)\end{array}$ & $\begin{array}{l}\text { LIS } \\
\text { LYS } \\
(\%)\end{array}$ & $\begin{array}{l}\text { MET } \\
M E T \\
(\%)\end{array}$ & $\begin{array}{c}\mathrm{M}+\mathrm{C} \\
M e t+C y s \\
(\%)\end{array}$ & $\begin{array}{l}\text { TRE } \\
T H R \\
(\%)\end{array}$ & $\begin{array}{c}\text { ARG } \\
A R G \\
(\%)\end{array}$ & $\begin{array}{l}\text { HIS } \\
H Y S \\
(\%)\end{array}$ & $\begin{array}{l}\text { ILE } \\
\text { ILE } \\
(\%)\end{array}$ & $\begin{array}{l}\text { LEU } \\
\text { LEU } \\
(\%)\end{array}$ & $\begin{array}{l}\text { FEN } \\
P H E \\
(\%)\end{array}$ & $\begin{array}{l}\text { VAL } \\
V A L \\
(\%)\end{array}$ \\
\hline $\begin{array}{l}\text { Milho } 1 \\
\text { Corn } 1\end{array}$ & 87,86 & 9,82 & 0,24 & 0,19 & 0,42 & 0,35 & 0,39 & 0,31 & 0,34 & 1,27 & 0,49 & 0,46 \\
\hline $\begin{array}{l}\text { Milho } 2 \\
\text { Corn } 2\end{array}$ & 86,65 & 8,07 & 0,26 & 0,20 & 0,41 & 0,32 & 0,40 & 0,24 & 0,30 & 0,96 & 0,38 & 0,42 \\
\hline $\begin{array}{l}\text { Milho QPM } \\
\text { Quality protein maize }\end{array}$ & 88,52 & 7,67 & 0,33 & 0,13 & 0,30 & 0,33 & 0,45 & 0,32 & 0,26 & 0,68 & 0,31 & 0,45 \\
\hline $\begin{array}{l}\text { Milho pré-cozido } \\
\text { Pre-cooked corn }\end{array}$ & 88,82 & 8,43 & 0,25 & 0,18 & 0,36 & 0,33 & 0,36 & 0,30 & 0,31 & 1,06 & 0,42 & 0,43 \\
\hline $\begin{array}{l}\text { Farelo de glúten } 60 \\
\text { Corn gluten feed }\end{array}$ & 92,09 & 62,15 & 0,99 & 1,29 & 2,22 & 2,17 & 1,81 & 1,24 & 2,71 & 10,74 & 4,01 & 2,79 \\
\hline $\begin{array}{l}\text { Farelo de glúten } 21 \\
\text { Corn gluten meal }\end{array}$ & 85,59 & 24,00 & 0,49 & 0,36 & 0,88 & 0,87 & 0,65 & 0,82 & 0,73 & 2,15 & 0,80 & 1,19 \\
\hline $\begin{array}{l}\text { Gérmen milho }(\mathrm{GM}) \\
\text { Corn germ - CG }\end{array}$ & 89,47 & 8,96 & 0,34 & 0,18 & 0,36 & 0,36 & 0,53 & 0,28 & 0,32 & 0,94 & 0,41 & 0,47 \\
\hline $\begin{array}{l}\text { Gérmen de milho fino } \\
\text { Fine } C G\end{array}$ & 90,65 & 9,73 & 0,50 & 0,21 & 0,43 & 0,39 & 0,74 & 0,32 & 0,33 & 0,85 & 0,43 & 0,54 \\
\hline $\begin{array}{l}\text { GM desengordurado } \\
\text { Free-fat } C G\end{array}$ & 90,16 & 10,85 & 0,52 & 0,20 & 0,40 & 0,43 & 0,70 & 0,32 & 0,35 & 0,91 & 0,46 & 0,55 \\
\hline $\begin{array}{l}\text { Milheto } 1 \\
\text { Millet } 1\end{array}$ & 89,47 & 12,40 & 0,36 & 0,24 & 0,43 & 0,47 & 0,48 & 0,25 & 0,51 & 1,21 & 0,59 & 0,67 \\
\hline $\begin{array}{l}\text { Milheto } 2 \\
\text { Millet } 2 \\
\end{array}$ & 88,52 & 13,41 & 0,41 & 0,30 & 0,54 & 0,54 & 0,59 & 0,31 & 0,57 & 1,36 & 0,67 & 0,75 \\
\hline
\end{tabular}

${ }^{1}$ Análises realizadas no Laboratório da Eurolysine (Amiens - França).

2 MS (matéria seca), PB (proteína bruta), LIS (lisina), MET (metionina), M+C (metionina + cistina), TRE (treonina), ARG (arginina), HIS (histidina), ILE (isoleucina), LEU (leucina), FEN (fenilalanina), VAL (valina).

1 Analyzed in the Eurolysine Laboratory (Amiens - France).

${ }^{2}$ DM (dry matter), CP (crude protein), LYS (lisina), MET (methionine), Met+Cys (methionine + cystine), THR(treonine), ARG (arginine), HIS (hystidine), ILE (isoleucyne), LEU (leucyne), PHE (phenylalanine), VAL (valyne).

BERTECHINI et al. (1999), porém o teor de metionina + cistina encontrado pelos referidos autores foi $23,3 \%$ superior aos obtidos nesta pesquisa. Nota-se, ainda, em relação aos milhos analisados, inferioridade de 25,0 e $61,8 \%$ no conteúdo de metionina + cistina e leucina do QPM em relação à média dos demais. É evidente, ainda, relação direta do conteúdo de aminoácidos, essenciais e não-essenciais, com o teor de proteína bruta das amostras.

Com exceção da histidina, cuja composição foi semelhante, o milheto apresentou uma composição aminoacídica superior à média das amostras do milho, o que possivelmente pode justificar ainda mais o interesse dos nutricionistas, nos últimos anos, em avaliar a utilização deste cereal nas dietas de aves, em substituição ao milho. As amostras de milheto 1 e 2 apresentaram, em média, composição em aminoácidos essenciais $42,7 \%$ superior à média das quatro amos- tras de milho, o mesmo ocorrendo com os nãoessenciais, cujos valores médios das amostras de milheto foram $49,7 \%$ superiores à média das amostras de milho.

Os teores médios de aminoácidos das duas amostras de milheto do presente trabalho assemelharam-se aos valores apresentados por ADEOLA e ROGLER (1994) e foram superiores aos descritos por DALE (1999). Observou-se também variação em relação aos valores citados por SMITH et al. (1989), NRC (1994) e LAWRENCE et al. (1995). Entretanto, vale ressaltar que, dos autores citados acima, somente uma das amostras de milheto analisado por ADEOLA e ROGLER (1994) apresentou teor de proteína bruta semelhante ao do presente trabalho, quando comparado à amostra de milheto 2 . Certamente, esta variabilidade na composição aminoacídica do milheto está relacionada ao seu conteúdo de proteína. 
Tabela 2 - Conteúdo de aminoácidos não essenciais totais do milho e subprodutos e do milheto Table 2 - Total non essential amino acids content of the corn and byproducts and of the millet

\begin{tabular}{|c|c|c|c|c|c|c|c|c|c|}
\hline \multirow[b]{2}{*}{$\begin{array}{l}\text { Alimento } \\
\text { Feedstuff }\end{array}$} & \multicolumn{9}{|c|}{$\begin{array}{c}\text { Aminoácidos }{ }^{1,2} \\
\text { Amino acids }\end{array}$} \\
\hline & $\begin{array}{l}\text { MS } \\
D M \\
(\%)\end{array}$ & $\begin{array}{l}\mathrm{PB} \\
C P \\
(\%)\end{array}$ & $\begin{array}{l}\text { CIS } \\
C Y S \\
(\%)\end{array}$ & $\begin{array}{c}\text { ALA } \\
A L A \\
(\%)\end{array}$ & $\begin{array}{l}\text { ASP } \\
A S P \\
(\%)\end{array}$ & $\begin{array}{l}\text { GLU } \\
G L U \\
(\%)\end{array}$ & $\begin{array}{l}\text { GLI } \\
G L Y \\
(\%)\end{array}$ & $\begin{array}{l}\text { SER } \\
\text { SER } \\
(\%)\end{array}$ & $\begin{array}{l}\text { TIR } \\
\text { TYR } \\
(\%)\end{array}$ \\
\hline $\begin{array}{l}\text { Milho } 1 \\
\text { Corn } 1\end{array}$ & 87,86 & 9,82 & 0,23 & 0,73 & 0,60 & 1,81 & 0,39 & 0,49 & 0,28 \\
\hline $\begin{array}{l}\text { Milho } 2 \\
\text { Corn } 2\end{array}$ & 86,65 & 8,07 & 0,20 & 0,58 & 0,54 & 1,43 & 0,35 & 0,41 & 0,24 \\
\hline $\begin{array}{l}\text { Milho QPM } \\
\text { Quality protein maize }\end{array}$ & 88,52 & 7,67 & 0,17 & 0,46 & 0,57 & 1,20 & 0,40 & 0,34 & 0,19 \\
\hline $\begin{array}{l}\text { Milho pré-cozido } \\
\text { Pre-cooked corn }\end{array}$ & 88,82 & 8,43 & 0,19 & 0,64 & 0,58 & 1,55 & 0,34 & 0,43 & 0,24 \\
\hline $\begin{array}{l}\text { Farelo de glúten } 60 \\
\text { Corn gluten feed }\end{array}$ & 92,09 & 62,15 & 0,93 & 5,55 & 3,89 & 13,79 & 1,68 & 3,31 & 3,16 \\
\hline $\begin{array}{l}\text { Farelo de glúten } 21 \\
\text { Corn gluten meal }\end{array}$ & 85,59 & 24,00 & 0,52 & 1,77 & 1,16 & 3,74 & 1,06 & 0,87 & 0,40 \\
\hline $\begin{array}{l}\text { Gérmen de milho (GM) } \\
\text { Corn germ - CG }\end{array}$ & 89,47 & 8,96 & 0,19 & 0,60 & 0,62 & 1,49 & 0,42 & 0,42 & 0,27 \\
\hline $\begin{array}{l}\text { Gérmen de milho fino } \\
\text { Fine } C G\end{array}$ & 90,65 & 9,73 & 0,21 & 0,65 & 0,72 & 1,46 & 0,55 & 0,47 & 0,26 \\
\hline $\begin{array}{l}\text { GM desengordurado } \\
\text { Free-fat } C G\end{array}$ & 90,16 & 10,85 & 0,20 & 0,69 & 0,84 & 1,63 & 0,56 & 0,50 & 0,27 \\
\hline $\begin{array}{l}\text { Milheto } 1 \\
\text { Millet } 1\end{array}$ & 89,47 & 12,40 & 0,19 & 0,94 & 1,00 & 2,31 & 0,40 & 0,55 & 0,25 \\
\hline $\begin{array}{l}\text { Milheto } 2 \\
\text { Millet } 2\end{array}$ & 88,52 & 13,41 & 0,25 & 1,07 & 1,13 & 2,62 & 0,34 & 0,63 & 0,32 \\
\hline
\end{tabular}

\footnotetext{
1 Análises realizadas no Laboratório da Eurolysine (Amiens - França).

2 MS (matéria seca), PB (proteína bruta), CIS (cistina), ALA (alanina), ASP (ácido aspártico), GLU (ácido glutâmico), GLI (glicina), SER (serina), TIR (tirosina).

1 Analyzed in the Eurolysine Laboratory (Amiens - France).

${ }^{2}$ DM (dry matter), CP (crude protein), CYS (cystine), ALA (alanine), ASP (aspartic acid), GLU (glutamic acid), GLY (glycine), SER (seryne), TYR (tyrosine).
}

Quando comparados à literatura, nota-se certa variação nos teores de aminoácidos encontrados para o farelo de glúten 21 (ROSTAGNO et al., 1983; NRC, 1994 e 1998; DALE, 1999) e o farelo de glúten 60 (ROSTAGNO et al., 1983; EMBRAPA, 1991; FISCHER JR. et al., 1998 e DALE, 1999). No que se refere ao gérmen de milho, a literatura é escassa e, tratando-se de um subproduto, conforme relatado por BATH et al. (1999), a composição de um alimento pode variar em função do processamento e, também, das formas de obtenção, o que torna difícil uma comparação das amostras de gérmen com a literatura. Entretanto, em relação às amostras de milho, nota-se que, de maneira geral, as amostras de gérmen apresentaram composição ligeiramente superior em aminoácidos, tanto essenciais como não-essenciais.

Os alimentos utilizados nas formulações de rações são, muitas vezes, escolhidos em função de suas características nutricionais, determinadas pelas aná- lises químicas, as quais, entretanto, não consideram a utilização dos aminoácidos pelo animal, durante os processos de digestão e absorção, afetados por diferentes fatores. Os coeficientes de digestibilidade verdadeira dos aminoácidos essenciais e não-essenciais dos alimentos avaliados neste trabalho estão apresentados nas Tabelas 3 e 4, respectivamente.

Quando se compararam as literaturas nacional e estrangeira da última década, é possível notar certas variações nos coeficientes de digestibilidade verdadeira dos aminoácidos nos milhos (ALBINO et al., 1992; DEGUSSA, 1993; RHÔNE POULENC, 1993; NRC, 1994; ROSTAGNO et al., 1995; FISCHER JR. et al., 1998; BELLAVER et al., 1998; DALE, 1999), farelo de glúten 21 (RHÔNE POULENC, 1993; DEGUSSA, 1993; NRC, 1994; DALE, 1999) e farelo de glúten 60 (RHÔNE POULENC, 1993; DEGUSSA, 1993; NRC, 1994; FISCHER JR. et al., 1998; DALE, 1999). Não constam da literatura coeficientes de 


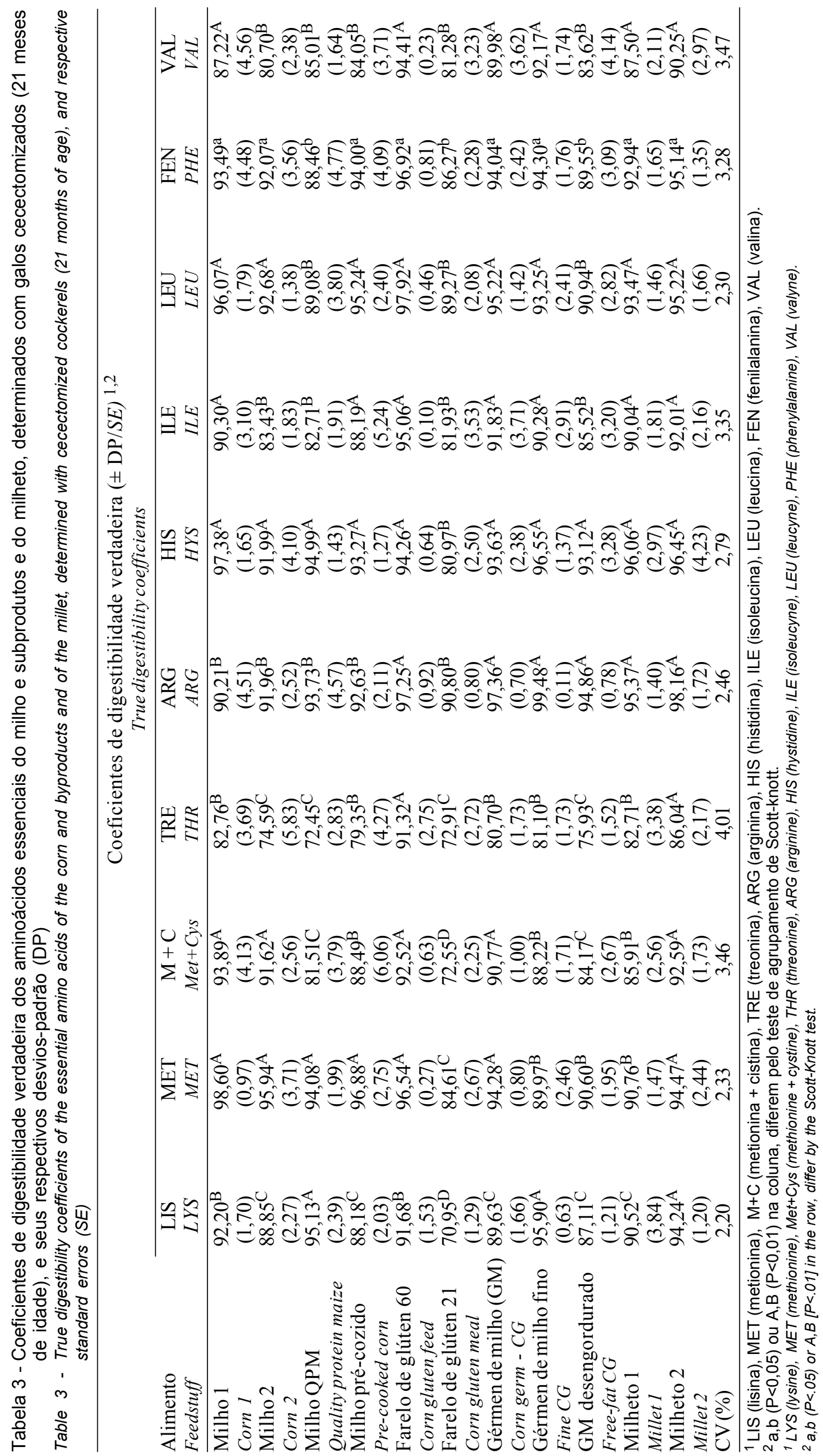


Tabela 4 - Coeficientes de digestibilidade verdadeira dos aminoácidos não-essenciais do milho e subprodutos e do milheto, determinados com galos cecectomizados (21 meses de idade), e seus respectivos desvios-padrão (DP)

Table 4 - True digestibility coefficients of the non-essential amino acids of the corn and byproducts and of the millet, determined with cecectomized cockerels (21 months of age), and respective standard errors (SE)

\begin{tabular}{|c|c|c|c|c|c|c|}
\hline \multirow{3}{*}{$\begin{array}{l}\text { Alimento } \\
\text { Feedstuff }\end{array}$} & \multicolumn{6}{|c|}{$\begin{array}{c}\text { Coeficientes de digestibilidade verdadeira }( \pm \mathrm{DP} / S E)^{1,2} \\
\text { True digestibility coefficients }\end{array}$} \\
\hline & CIS & ALA & ASP & GLU & SER & TIR \\
\hline & CYS & $A L A$ & $A S P$ & $G L U$ & SER & TYR \\
\hline Milho 1 & $84,12^{\mathrm{A}}(3,36)$ & $93,41^{\mathrm{B}}(0,86)$ & $88,40^{\mathrm{B}}(2,94)$ & $95,86^{\mathrm{A}}(2,08)$ & $89,15^{\mathrm{B}}(3,49)$ & $93,22^{\mathrm{A}}(7,60)$ \\
\hline Corn 1 & & & & & & \\
\hline $\begin{array}{l}\text { Milho } 2 \\
\text { Corn } 2\end{array}$ & $84,14^{\mathrm{A}}(2,53)$ & $89,41^{\mathrm{C}}(1,42)$ & $84,48^{\mathrm{D}}(3,07)$ & $94,59^{\mathrm{A}}(1,18)$ & $79,50^{\mathrm{C}}(4,32)$ & $91,87^{\mathrm{A}}(1,83)$ \\
\hline $\begin{array}{l}\text { Milho QPM } \\
\text { Ouality protei }\end{array}$ & $73,08^{\mathrm{B}}(5,35)$ & $88,56^{\mathrm{C}}(1,60)$ & $89,50^{\mathrm{B}}(1,89)$ & $94,05^{\mathrm{A}}(2,03)$ & $79,82^{\mathrm{C}}(2,70)$ & $89,56^{\mathrm{B}}(2,89)$ \\
\hline $\begin{array}{l}\text { Quality protein malz } \\
\text { Milho pré-cozido } \\
\text { Pre-cooked corn }\end{array}$ & $77,60^{\mathrm{B}}(4,16)$ & $90,40^{\mathrm{B}}(3,88)$ & $88,66^{\mathrm{B}}(0,29)$ & $95,82^{\mathrm{A}}(0,43)$ & $86,78^{\mathrm{B}}(0,71)$ & $94,68^{\mathrm{A}}(1,54)$ \\
\hline $\begin{array}{l}\text { Farelo de glúten } 60 \\
\text { Corn gluten feed }\end{array}$ & $86,96^{\mathrm{A}}(2,13)$ & $97,34^{\mathrm{A}}(0,22)$ & $94,19^{\mathrm{A}}(1,12)$ & $97,55^{\mathrm{A}}(0,15)$ & $95,41^{\mathrm{A}}(1,27)$ & $97,60^{\mathrm{A}}(0,39)$ \\
\hline $\begin{array}{l}\text { Farelo de glúten } 21 \\
\text { Corn gluten meal }\end{array}$ & $64,65^{\mathrm{C}}(3,84)$ & $85,09^{\mathrm{D}}(1,88)$ & $75,26^{\mathrm{C}}(2,51)$ & $82,83^{\mathrm{B}}(0,45)$ & $81,17^{\mathrm{C}}(1,53)$ & $85,61^{\mathrm{B}}(2,25)$ \\
\hline $\begin{array}{l}\text { Gérmen milho(GM) } \\
\text { Corn germ - CG }\end{array}$ & $87,45^{\mathrm{A}}(1,21)$ & $91,73^{\mathrm{B}}(2,33)$ & $91,60^{\mathrm{A}}(0,58)$ & $95,44^{\mathrm{A}}(0,42)$ & $87,91^{\mathrm{B}}(1,61)$ & $93,65^{\mathrm{A}}(2,69)$ \\
\hline $\begin{array}{l}\text { Gérmen de milho fino } \\
\text { Fine } C G\end{array}$ & $85,22^{\mathrm{A}}(1,76)$ & $91,70^{\mathrm{B}}(0,98)$ & $92,54^{\mathrm{A}}(0,73)$ & $94,84^{\mathrm{A}}(0,40)$ & $89,66^{\mathrm{B}}(1,05)$ & $95,57^{\mathrm{A}}(2,04)$ \\
\hline $\begin{array}{l}\text { GM desengordurado } \\
\text { Free-fat } C G\end{array}$ & $78,42^{\mathrm{B}}(3,10)$ & $85,33^{\mathrm{D}}(3,90)$ & $86,58^{\mathrm{B}}(3,97)$ & $93,35^{\mathrm{A}}(3,00)$ & $83,79^{\mathrm{C}}(2,47)$ & $89,61^{\mathrm{B}}(4,35)$ \\
\hline $\begin{array}{l}\text { Milheto } 1 \\
\text { Millet } 1\end{array}$ & $81,60^{\mathrm{A}}(3,97)$ & $90,41^{\mathrm{B}}(1,69)$ & $87,97^{\mathrm{B}}(2,20)$ & $94,94^{\mathrm{A}}(0,98)$ & $90,88^{\mathrm{B}}(2,47)$ & $86,39^{\mathrm{B}}(2,49)$ \\
\hline $\begin{array}{l}\text { Milheto } 2 \\
\text { Millet } 2\end{array}$ & $90,98^{\mathrm{A}}(1,76)$ & $91,51^{\mathrm{B}}(1,43)$ & $93,37^{\mathrm{A}}(1,13)$ & $97,43^{\mathrm{A}}(0,92)$ & $93,94^{\mathrm{A}}(0,60)$ & $93,09^{\mathrm{A}}(3,37)$ \\
\hline CV $(\%)$ & 3,99 & 2,37 & 2,46 & 1,48 & 2,66 & 3,67 \\
\hline
\end{tabular}

1 CIS (cistina), ALA (alanina), SER (serina), GLU (ácido glutâmico), ASP (ácido aspártico), TIR (tirosina).

2 A,B na coluna, diferem pelo teste de agrupamento de Scott-knott $(P<0,01)$.

1 CYS (cystine), ALA (alanine), SER (serine), GLU (glutamic acid), ASP (aspartic acid), TYR (tyrosine).

${ }^{2} A, B$ in the row, differing by the Scott-Knott test.

digestibilidade para amostras de gérmen de milho de composição semelhante à do presente experimento, $\mathrm{o}$ mesmo ocorrendo com o milheto, em que a literatura ainda é escassa em relação a aminoácidos digestíveis.

Quando se aplica o teste de agrupamento de Scott-Knott, nota-se variação entre os alimentos e mesmo entre os aminoácidos de um mesmo alimento, nos coeficientes de digestibilidade, o que mostra a importância de se considerar a digestibilidade dos aminoácidos nas formulações. Esta diferença nos coeficientes de digestibilidade de um mesmo alimento, possivelmente, poderia estar associada, entre outros fatores, à grande variação nos valores de excreção endógena de aminoácidos, determinadas com aves em jejum, o que não padroniza as perdas endógenas (FISCHER JR., 1997) e, conseqüentemente, leva a estimativas diferenciadas. Entretanto, quando se observam os coeficientes de variação obtidos no presente trabalho, pode-se afirmar que o método de alimentação forçada com galos adultos apresentou boa precisão e eficácia nas estimativas dos coeficientes de digestibilidade verdadeira dos aminoácidos.

De maneira geral, os aminoácidos lisina, metionina + cistina e treonina foram os que apresentaram maiores variações entre os alimentos, sendo o farelo de glúten 21 o alimento com menor digestibilidade dos aminoácidos, independentemente da essencialidade destes. Isto possivelmente pode estar associado ao elevado teor de fibra, quando comparado aos demais alimentos estudados. A fibra pode influir nos valores de digestibilidade, devido a alterações na excreção endógena dos animais (PARSONS, 1984; COON, 1991; JOHNSON, 1992).

Quando se comparam os quatro milhos estudados, observa-se que houve variações na digestibilidade da maioria dos aminoácidos, tanto essenciais quanto não-essenciais, com algumas ex- 
ceções (metionina, arginina, histidina, ácidos aspártico e glutâmico). Estes resultados são importantes por mostrar que não só a energia, como descrito por LEESON et al. (1993), mas também outros nutrientes podem variar em sua digestibilidade, em função de diferentes lotes, variedades ou processamentos. A lisina do milho QPM foi mais digestível que a das demais amostras de milho, no entanto, este comportamento não foi observado para os outros aminoácidos, nos quais o QPM apresentou coeficientes de digestibilidade semelhantes ou inferiores aos outros milhos.

As digestibilidades dos aminoácidos do milheto, tanto os essenciais quanto os não-essenciais, foi alta, particularmente na amostra 2 , a qual foi muito semelhante ao farelo de glúten 60, que apresenta ótimo aporte em aminoácidos e na digestibilidade destes, mostrando mais uma vez a importância de se considerar o milheto como fonte alternativa nas formula- ções. A amostra de gérmen de milho desengordurado apresentou menores coeficientes de digestibilidade que as outras duas amostras, com exceção da arginina, histidina e do ácido glutâmico, que foram semelhantes. Esta diferença pode, possivelmente, estar associada ao processo de desengorduramento do gérmen.

Nas Tabelas 5 e 6, estão apresentados os conteúdos de aminoácidos digestíveis verdadeiros e, de acordo com ROSTAGNO et al. (1999), já é uma realidade que os valores de aminoácidos dos alimentos devem ser expressos em termos de aminoácidos digestíveis, e não totais, tornando os valores obtidos no presente trabalho de grande utilidade nas formulações. De acordo com DEGUSSA (1993), o valor de uma proteína alimentar depende de seu conteúdo em aminoácidos essenciais e sua disponibilidade para o metabolismo das aves. Quando se consideram os aminoácidos em função de sua digestibilidade, pode-se garantir o fornecimento adequado destes aos ani-

Tabela 5 - Conteúdo de aminoácidos essenciais digestíveis do milho e subprodutos e do milheto

Table 5 - Digestible essential amino acids content of the corn and byproducts and of the millet

\begin{tabular}{|c|c|c|c|c|c|c|c|c|c|c|c|c|}
\hline \multirow[b]{2}{*}{$\begin{array}{l}\text { Alimento } \\
\text { Feedstuff }\end{array}$} & \multicolumn{12}{|c|}{$\begin{array}{l}\text { Aminoácidos }{ }^{1,2} \\
\text { Amino acids }{ }^{1,2}\end{array}$} \\
\hline & $\begin{array}{l}D M \\
M S \\
(\%)\end{array}$ & $\begin{array}{l}C P \\
P B \\
(\%)\end{array}$ & $\begin{array}{l}L Y S \\
L I S \\
(\%)\end{array}$ & $\begin{array}{c}M E T \\
M E T \\
(\%)\end{array}$ & $\begin{array}{c}M e t+C y s \\
M+C \\
(\%)\end{array}$ & $\begin{array}{l}\text { THR } \\
\text { TRE } \\
(\%)\end{array}$ & $\begin{array}{c}A R G \\
A R G \\
(\%)\end{array}$ & $\begin{array}{c}H Y S \\
H I S \\
(\%)\end{array}$ & $\begin{array}{l}I L E \\
I L E \\
(\%)\end{array}$ & $\begin{array}{l}L E U \\
L E U \\
(\%)\end{array}$ & $\begin{array}{l}P H E \\
F E N \\
(\%)\end{array}$ & $\begin{array}{l}V A L \\
V A L \\
(\%)\end{array}$ \\
\hline $\begin{array}{l}\text { Milho } 1 \\
\text { Corn } 1\end{array}$ & 87,86 & 9,82 & 0,22 & 0,18 & 0,40 & 0,29 & 0,35 & 0,31 & 0,31 & 1,22 & 0,46 & 0,40 \\
\hline $\begin{array}{l}\text { Milho } 2 \\
\text { Corn } 2\end{array}$ & 86,65 & 8,07 & 0,23 & 0,19 & 0,38 & 0,24 & 0,37 & 0,23 & 0,25 & 0,91 & 0,35 & 0,34 \\
\hline $\begin{array}{l}\text { Milho QPM } \\
\text { Quality protein maize }\end{array}$ & 88,52 & 7,67 & 0,32 & 0,12 & 0,25 & 0,24 & 0,42 & 0,31 & 0,21 & 0,60 & 0,28 & 0,38 \\
\hline $\begin{array}{l}\text { Milho pré-cozido } \\
\text { Pre-cooked corn }\end{array}$ & 88,82 & 8,43 & 0,22 & 0,17 & 0,32 & 0,26 & 0,34 & 0,28 & 0,27 & 1,01 & 0,39 & 0,36 \\
\hline $\begin{array}{l}\text { Farelo de glúten } 60 \\
\text { Corn gluten feed }\end{array}$ & 92,09 & 62,15 & 0,91 & 1,24 & 2,05 & 1,98 & 1,76 & 1,17 & 2,57 & 10,51 & 3,89 & 2,63 \\
\hline $\begin{array}{l}\text { Farelo de glúten } 21 \\
\text { Corn gluten meal }\end{array}$ & 85,59 & 24,00 & 0,35 & 0,31 & 0,64 & 0,64 & 0,59 & 0,66 & 0,60 & 1,92 & 0,69 & 0,97 \\
\hline $\begin{array}{l}\text { Gérmen Milho }(\mathrm{GM}) \\
\text { Corn germ - CG }\end{array}$ & 89,47 & 8,96 & 0,30 & 0,17 & 0,33 & 0,29 & 0,51 & 0,26 & 0,29 & 0,89 & 0,39 & 0,42 \\
\hline $\begin{array}{l}\text { Gérmen de milho fino } \\
\text { Fine } C G\end{array}$ & 90,65 & 9,73 & 0,48 & 0,19 & 0,38 & 0,32 & 0,73 & 0,31 & 0,30 & 0,79 & 0,40 & 0,50 \\
\hline $\begin{array}{l}\text { GM desengordurado } \\
\text { Free-fat } C G\end{array}$ & 90,16 & 10,85 & 0,46 & 0,18 & 0,34 & 0,33 & 0,66 & 0,30 & 0,30 & 0,82 & 0,41 & 0,46 \\
\hline $\begin{array}{l}\text { Milheto } 1 \\
\text { Millet } 1\end{array}$ & 89,47 & 12,40 & 0,33 & 0,22 & 0,37 & 0,39 & 0,46 & 0,24 & 0,46 & 1,13 & 0,54 & 0,59 \\
\hline $\begin{array}{l}\text { Milheto } 2 \\
\text { Millet } 2\end{array}$ & 88,52 & 13,41 & 0,38 & 0,28 & 0,50 & 0,47 & 0,58 & 0,30 & 0,53 & 1,30 & 0,64 & 0,68 \\
\hline
\end{tabular}

1 Valores calculados por meio dos coeficientes de digestibilidade determinados in vivo e conteúdo de aminoácidos totais dos alimentos.

2 MS (matéria seca), PB (proteína bruta), LIS (lisina), MET (metionina), M+C (metionina + cistina), TRE (treonina), ARG (arginina), HIS (histidina), ILE (isoleucina), LEU (leucina), FEN (fenilalanina), VAL (valina), AAE (total dos aminoácidos essenciais).

1 Values calculated by the digestibility coefficients determined in vivo and total amino acids content of the feedstuffs.

2 DM (dry matter), CP (crude protein), LYS (lisina), MET (methionine), Met+Cys (methionine + cystine), THR (threonine), ARG (arginine), HIS (hystidine), ILE (isoleucyne), LEU (leucyne), PHE (phenylalanine), VAL (valyne). 
Tabela 6 - Conteúdo de aminoácidos não-essenciais digestíveis do milho e subprodutos e do milheto Table 6 - Digestible non-essential amino acids content of the corn and byproducts and of the millet

\begin{tabular}{|c|c|c|c|c|c|c|}
\hline \multirow[b]{2}{*}{$\begin{array}{l}\text { Alimento } \\
\text { Feedstuff }\end{array}$} & \multicolumn{6}{|c|}{$\begin{array}{c}\text { Aminoácidos } \\
\text { Amino acids }\end{array}$} \\
\hline & $\begin{array}{l}\text { CIS } \\
C Y S \\
(\%)\end{array}$ & $\begin{array}{c}\text { ALA } \\
A L A \\
(\%)\end{array}$ & $\begin{array}{l}\text { ASP } \\
A S P \\
(\%)\end{array}$ & $\begin{array}{c}\text { GLU } \\
G L U \\
(\%)\end{array}$ & $\begin{array}{l}\text { SER } \\
\text { SER } \\
(\%)\end{array}$ & $\begin{array}{l}\text { TIR } \\
\text { TYR } \\
(\%)\end{array}$ \\
\hline $\begin{array}{l}\text { Milho } 1 \\
\text { Corn } 1\end{array}$ & 0,19 & 0,68 & 0,53 & 1,73 & 0,44 & 0,27 \\
\hline $\begin{array}{l}\text { Milho } 2 \\
\text { Corn } 2\end{array}$ & 0,17 & 0,52 & 0,46 & 1,35 & 0,33 & 0,22 \\
\hline $\begin{array}{l}\text { Milho QPM } \\
\text { Quality protein maize }\end{array}$ & 0,13 & 0,41 & 0,51 & 1,13 & 0,27 & 0,17 \\
\hline $\begin{array}{l}\text { Milho pré-cozido } \\
\text { Pre-cooked corn }\end{array}$ & 0,14 & 0,57 & 0,52 & 1,48 & 0,37 & 0,23 \\
\hline $\begin{array}{l}\text { Farelo de glúten } 60 \\
\text { Corn gluten feed }\end{array}$ & 0,81 & 5,41 & 3,66 & 13,46 & 3,15 & 3,09 \\
\hline $\begin{array}{l}\text { Farelo de glúten } 21 \\
\text { Corn gluten meal }\end{array}$ & 0,34 & 1,51 & 0,87 & 3,10 & 0,71 & 0,34 \\
\hline $\begin{array}{l}\text { Gérmen de milho (GM) } \\
\text { Corn germ - CG }\end{array}$ & 0,16 & 0,55 & 0,57 & 1,43 & 0,37 & 0,25 \\
\hline $\begin{array}{l}\text { Gérmen de milho fino } \\
\text { Fine } C G\end{array}$ & 0,18 & 0,60 & 0,66 & 1,39 & 0,42 & 0,25 \\
\hline $\begin{array}{l}\text { GM desengordurado } \\
\text { Free fat } C G\end{array}$ & 0,16 & 0,59 & 0,73 & 1,52 & 0,42 & 0,24 \\
\hline $\begin{array}{l}\text { Milheto } 1 \\
\text { Millet } 1\end{array}$ & 0,15 & 0,85 & 0,88 & 2,19 & 0,50 & 0,22 \\
\hline $\begin{array}{l}\text { Milheto } 2 \\
\text { Millet } 2\end{array}$ & 0,22 & 0,98 & 1,05 & 2,55 & 0,59 & 0,29 \\
\hline
\end{tabular}

mais. O farelo de glúten 21, por exemplo, apresenta em média pouco mais de $80 \%$ de aminoácidos digestíveis, em relação ao conteúdo total analisado. Por outro lado, o farelo de glúten 60 , com aminoácidos de digestibilidade elevada, situa-se mais próximo daquela composição bruta (aproximadamente $5 \%$ de diferença), por apresentar alta digestibilidade de seus aminoácidos. Esta observação reforça a colocação de ROSTAGNO (1990) de que, quando se utilizam alimentos não-convencionais nas formulações, o uso de aminoácidos digestíveis é mais vantajoso.

Nas Tabelas 7 e 8, estão apresentadas as equações para predizer o conteúdo em aminoácidos totais e digestíveis, respectivamente, do milho e subprodutos, calculadas em função da composição destes alimentos em proteína bruta (PB), fibra bruta (FB), extrato etéreo (EE)e matéria mineral (MM). Com exceção da lisina e arginina, para os quais os valores dos coeficientes de determinação $\left(\mathrm{R}^{2}\right)$ foram os mais baixos nas equações estabelecidas, em função da composição em proteína bruta, para predizer o conteúdo de aminoácidos totais e digestíveis verdadeiros nos alimentos $(0,83$ e 0,$90 ; 0,78$ e 0,88 , respectivamente), as demais equações ajustadas explicaram mais de $93 \%$ da variação nos teores destes aminoácidos, seja com a PB isoladamente ou em combinação com as demais variáveis (FB, EE, MM).

A proteína bruta dos alimentos foi altamente correlacionada com os aminoácidos destes, variando de 91,33 a 99,97 e de 88,35 a $99,70 \%$, respectivamente para lisina e treonina totais e digestíveis. A fibra bruta, com exceção da lisina total $(1,96 \%)$, mostrou baixa correlação negativa $(2,33$ a 16,04 e 9,98 a $19,28 \%$ ), inversamente ao EE, o qual esteve correlacionado positivamente $(3,83$ a 21,67 e 4,48 a $26,18 \%$, respectivamente) para aminoácidos totais e digestíveis. Estas correlações são superiores àquelas apresentadas nas equações descritas pelo NRC (1998), para o milho (lisina, treonina, metionina e metionina + cistina), farelo de glúten 60 (treonina) e farelo de glúten 
Tabela 7 - Equações de predição do conteúdo de lisina (LIS), metionina (MET), metionina + cistina (M+C), treonina (TRE) e arginina (ARG) totais do milho e subprodutos, com suas respectivas correlações, calculadas pela composição química dos alimentos

Table 7 - Prediction equations of total lysine (LYS), methionine (MET), methionine + cystine (Met + Cys), threonine (THR) and arginine (ARG) content of the corn and corn byproducts, with its respective correlations, calculated by the chemical composition

\begin{tabular}{|c|c|c|c|c|c|c|}
\hline & $\begin{array}{c}\text { Constante } \\
\text { Constant }\end{array}$ & $\begin{array}{l}\mathrm{PB} \\
C P\end{array}$ & $\begin{array}{l}\text { FB } \\
C F\end{array}$ & $\begin{array}{l}\mathrm{EE} \\
E E\end{array}$ & $\begin{array}{l}\mathrm{MM} \\
\text { Ash }\end{array}$ & $\mathrm{R}^{2}$ \\
\hline \multirow[t]{3}{*}{$\operatorname{LIS}(L Y S)$} & 0,13957 & 0,01149 & $-0,05928$ & 0,01717 & 0,06109 & 0,99 \\
\hline & 0,20915 & 0,01156 & $-0,62790$ & - & 0,06288 & 0,96 \\
\hline & 0,26488 & 0,01198 & - & - & - & 0,83 \\
\hline \multirow[t]{2}{*}{$\operatorname{MET}(M E T)$} & 0,03468 & 0,02023 & $-0,02273$ & - & - & 0,99 \\
\hline & $-0,01315$ & 0,02031 & - & - & - & 0,98 \\
\hline $\mathrm{M}+\mathrm{C}(\mathrm{Met}+\mathrm{Cys})$ & 0,07769 & 0,03448 & - & - & - & 0,99 \\
\hline TRE (THR) & 0,05576 & 0,03410 & - & - & - & 0,99 \\
\hline \multirow[t]{3}{*}{$\operatorname{ARG}(A R G)$} & 0,17835 & 0,02291 & $-0,11095$ & 0,02884 & 0,08357 & 0,99 \\
\hline & 0,29523 & 0,02302 & $-0,11684$ & - & 0,08659 & 0,98 \\
\hline & 0,30805 & 0,02370 & - & - & - & 0,90 \\
\hline \multicolumn{7}{|l|}{$\begin{array}{l}\text { Correlações } \\
\text { Correlations }\end{array}$} \\
\hline $\operatorname{LIS}(L Y S)$ & - & 0,9133 & 0,0196 & 0,2167 & 0,2324 & - \\
\hline $\operatorname{MET}(M E T)$ & - & 0,9900 & $-0,1604$ & 0,0537 & $-0,0820$ & - \\
\hline $\mathrm{M}+\mathrm{C}(\mathrm{Met}+\mathrm{Cys})$ & - & 0,9985 & $-0,0482$ & 0,0458 & $-0,0150$ & - \\
\hline $\operatorname{TRE}(T H R)$ & - & 0,9997 & $-0,0233$ & 0,0485 & 0,0306 & - \\
\hline $\mathrm{ARG}(A R G)$ & - & 0,9487 & $-0,1388$ & 0,2063 & 0,0485 & - \\
\hline
\end{tabular}

Tabela 8 - Equações de predição do conteúdo de lisina (LIS), metionina (MET), metionina + cistina (M+C), treonina (TRE) e arginina (ARG) digestíveis do milho e subprodutos, com suas respectivas correlações, calculadas pela composição química dos alimentos

Table 8 - Prediction equations of digestible lysine (LYS), methionine (MET), methionine + cystine (Met + Cys), threonine (THR) and arginine (ARG) content of the corn and corn byproducts, with its respective correlations, calculated by the chemical composition

\begin{tabular}{|c|c|c|c|c|c|c|}
\hline & $\begin{array}{c}\text { Constante } \\
\text { Constant }\end{array}$ & $\begin{array}{l}\text { PB } \\
C P\end{array}$ & $\begin{array}{l}\text { FB } \\
C F\end{array}$ & $\begin{array}{l}\mathrm{EE} \\
E E\end{array}$ & $\begin{array}{l}\mathrm{MM} \\
\text { Ash }\end{array}$ & $\mathrm{R}^{2}$ \\
\hline \multirow[t]{3}{*}{$\operatorname{LIS}(L Y S)$} & 0,13940 & 0,01012 & $-0,07589$ & 0,01874 & 0,06084 & 0,98 \\
\hline & 0,21533 & 0,01019 & $-0,07972$ & - & 0,06280 & 0,94 \\
\hline & 0,23518 & 0,01067 & - & - & - & 0,78 \\
\hline \multirow[t]{2}{*}{$\operatorname{MET}(M E T)$} & 0,03559 & 0,01941 & $-0,02737$ & - & - & 0,99 \\
\hline & $-0,02198$ & 0,01951 & - & - & - & 0,97 \\
\hline \multirow[t]{2}{*}{$\mathrm{M}+\mathrm{C}(\mathrm{Met}+\mathrm{Cys})$} & 0,11642 & 0,03131 & $-0,03268$ & - & - & 0,99 \\
\hline & 0,04767 & 0,03143 & - & - & - & 0,99 \\
\hline \multirow[t]{2}{*}{ TRE (THR) } & 0,02236 & 0,03149 & $-0,01889$ & - & - & 0,99 \\
\hline & $-0,01738$ & 0,03156 & - & - & - & 0,99 \\
\hline \multirow[t]{3}{*}{$\mathrm{ARG}(A R G)$} & 0,14558 & 0,02235 & $-0,11596$ & 0,03221 & 0,08429 & 0,99 \\
\hline & 0,27610 & 0,02247 & $-0,12254$ & - & 0,08766 & 0,97 \\
\hline & 0,28013 & 0,02318 & - & - & - & 0,88 \\
\hline \multicolumn{7}{|l|}{$\begin{array}{l}\text { Correlações } \\
\text { Correlations }\end{array}$} \\
\hline LIS & - & 0,8835 & $-0,1433$ & 0,2618 & 0,1039 & - \\
\hline \multicolumn{7}{|l|}{$L Y S$} \\
\hline MET & - & 0,9851 & $-0,1928$ & 0,0518 & $-0,1112$ & - \\
\hline \multicolumn{7}{|l|}{$M E T$} \\
\hline $\mathrm{M}+\mathrm{C}$ & - & 0,9909 & $-0,1512$ & 0,0489 & $-0,0845$ & - \\
\hline \multicolumn{7}{|l|}{$\mathrm{Met}+\mathrm{Cys}$} \\
\hline TRE & - & 0,9970 & $-0,0998$ & 0,0596 & $-0,0302$ & - \\
\hline \multicolumn{7}{|l|}{ THR } \\
\hline ARG & - & 0,9401 & $-0,1620$ & 0,2274 & 0,0312 & - \\
\hline$A R G$ & & & & & & \\
\hline
\end{tabular}


21 (lisina, treonina e metionina). Entretanto, vale ressaltar que, no presente trabalho, as equações foram estabelecidas para predizer os aminoácidos pela composição química de um grupo de alimentos, e não à partir de várias amostras de um mesmo alimento, sendo definida uma só equação que estimasse o conteúdo de cada aminoácido estudado (totais ou digestíveis) de todos os alimentos do grupo. Os NRC $(1994,1998)$ apresentam equações diferenciadas para cada alimento descrito anteriormente, o que pode ter levado a diferenças nas correlações.

Quando se consideraram as equações em que todas as variáveis independentes apresentaram significância no modelo ( $5 \%$ de probabilidade) nota-se que, após a PB, a $\mathrm{FB}$, seguida da MM, tiveram maior participação e somente o EE se ajustou significativamente para a lisina e arginina, total e digestível. Para a treonina e metionina + cistina totais, somente foi possível ajustar equações em que a PB foi a única variável independente no modelo.
Comparando as equações dos aminoácidos totais estudados apresentadas no NRC (1994), somente a treonina é destacada com uma equação ajustada com outras variáveis além da PB (umidade, EE e FB). Já o farelo de glúten 60 , para lisina e arginina, foi semelhante ao presente trabalho, ajustando equações com maior número de variáveis. NUNES (1999) observou bons ajustes de equações para predizer o conteúdo de aminoácidos digestíveis do grão de trigo e subprodutos com a PB e EE para a lisina e PB e FDN para os demais aminoácidos estudados.

O conteúdo dos aminoácidos totais analisados e digestíveis verdadeiros determinados no ensaio biológico com galos adultos cecectomizados e daqueles estimados por meio das equações de predição ajustadas, juntamente com a média da soma do quadrado dos desvios, está apresentado nas Tabelas 9 e 10 , respectivamente. Observa-se, pela média geral dos valores estimados e observados, que somente a

Tabela 9 - Estimativas do conteúdo de lisina, metionina, metionina + cistina (MET+CIS), treonina e arginina totais do milho e subprodutos, por meio das equações de predição, em função da composição química dos alimentos (expressos com base na matéria seca) ${ }^{1}$

Table 9 - Estimation of total lysine, methionine, methionine plus cystine (Met+Cys), threonine and arginine contents of the corn and corn byproducts, by the prediction equations, based on the chemical composition (in dry matter basis)

\begin{tabular}{|c|c|c|c|c|c|c|c|c|c|c|}
\hline \multirow[t]{2}{*}{$\begin{array}{l}\text { Alimento } \\
\text { Feedstuff }\end{array}$} & \multicolumn{2}{|c|}{$\begin{array}{l}\text { Lisina } \\
\text { Lysine }\end{array}$} & \multicolumn{2}{|c|}{$\begin{array}{l}\text { Metionina } \\
\text { Methionine }\end{array}$} & \multicolumn{2}{|c|}{$\begin{array}{c}\mathrm{MET}+\mathrm{CIS} \\
M e t+C y s\end{array}$} & \multicolumn{2}{|c|}{$\begin{array}{l}\text { Treonina } \\
\text { Threonine }\end{array}$} & \multicolumn{2}{|c|}{$\begin{array}{l}\text { Arginina } \\
\text { Arginine }\end{array}$} \\
\hline & $\mathrm{Obs}^{2}$ & $\mathrm{Est}^{3}$ & Obs & Est & Obs & Est & Obs & Est & Obs & Est \\
\hline $\begin{array}{l}\text { Milho } 1 \\
\text { Corn } 1\end{array}$ & 0,27 & 0,40 & 0,22 & 0,21 & 0,48 & 0,46 & 0,40 & 0,44 & 0,44 & 0,57 \\
\hline $\begin{array}{l}\text { Milho } 2 \\
\text { Corn } 2\end{array}$ & 0,30 & 0,38 & 0,23 & 0,18 & 0,47 & 0,40 & 0,37 & 0,37 & 0,46 & 0,53 \\
\hline $\begin{array}{l}\text { Milho QPM } \\
\text { Quality protein maize }\end{array}$ & 0,37 & 0,37 & 0,15 & 0,16 & 0,34 & 0,38 & 0,37 & 0,35 & 0,51 & 0,51 \\
\hline $\begin{array}{l}\text { Milho pré-cozido } \\
\text { Pre-cooked corn }\end{array}$ & 0,28 & 0,38 & 0,20 & 0,18 & 0,41 & 0,40 & 0,37 & 0,38 & 0,41 & 0,53 \\
\hline $\begin{array}{l}\text { Farelo de glúten } 60 \\
\text { Corn gluten feed }\end{array}$ & 1,08 & 1,07 & 1,40 & 1,36 & 2,41 & 2,40 & 2,36 & 2,36 & 1,97 & 1,91 \\
\hline $\begin{array}{l}\text { Farelo de glúten } 21 \\
\text { Corn gluten meal }\end{array}$ & 0,57 & 0,60 & 0,42 & 0,56 & 1,03 & 1,04 & 1,02 & 1,01 & 0,76 & 0,97 \\
\hline $\begin{array}{l}\text { Gérmen de milho }(\mathrm{GM}) \\
\text { Corn germ - CG }\end{array}$ & 0,38 & 0,38 & 0,20 & 0,19 & 0,40 & 0,42 & 0,40 & 0,40 & 0,59 & 0,55 \\
\hline $\begin{array}{l}\text { Gérmen de milho fino } \\
\text { Fine } C G\end{array}$ & 0,55 & 0,39 & 0,23 & 0,20 & 0,47 & 0,45 & 0,43 & 0,42 & 0,82 & 0,56 \\
\hline $\begin{array}{l}\text { GM desengordurado } \\
\text { Free-fat } C G\end{array}$ & 0,58 & 0,41 & 0,22 & 0,23 & 0,44 & 0,49 & 0,48 & 0,47 & 0,78 & 0,59 \\
\hline $\begin{array}{l}\text { Médias das estimativas } \\
\text { Estimates means }\end{array}$ & 0,49 & 0,49 & 0,36 & 0,36 & 0,72 & 0,72 & 0,69 & 0,69 & 0,75 & 0,75 \\
\hline $\begin{array}{l}\text { Médias } 4 \\
\text { Means }\end{array}$ & \multicolumn{2}{|c|}{0,00945} & \multicolumn{2}{|c|}{0,00278} & \multicolumn{2}{|c|}{0,00122} & \multicolumn{2}{|c|}{0,00025} & \multicolumn{2}{|c|}{0,02073} \\
\hline
\end{tabular}

1 Lisina $\left(\right.$ Lysine) $=0,26488+0,01198 \mathrm{~PB}\left(\mathrm{R}^{2}=0,83\right) ;$ Metionina (Methionine) $=-0,01315+0,02023 \mathrm{~PB}\left(\mathrm{R}^{2}=0,98\right) ; \mathrm{MET}+\mathrm{CIS}($ Met+Cys) $=0,07769$ $+0,03448 \mathrm{~PB}\left(R^{2}=0,99\right)$; Treonina (Threonine) = 0,05576 + 0,03410PB $\left(R^{2}=0,99\right)$; Arginina $($ Arginine $)=0,30805+0,02370 \mathrm{~PB}\left(\mathrm{R}^{2}=0,90\right)$

2 Conteúdo de aminoácidos digestíveis verdadeiros obtidos através dos coeficientes de digestibilidade determinados in vivo com galos adultos cecectomizados (Digestible amino acids content obtained by the digestibility coefficients determined in vivo with cecectomized adult cockerels).

3 Valores estimados pelas equações de predição (Estimated values by the prediction equations).

4 Médias da soma do quadrado dos desvios (Square deviation sum means).

Rev. bras. zootec., 30(6S):2046-2058, 2001 
Tabela 10 - Estimativas do conteúdo de lisina, metionina, metionina + cistina (MET+CIS), treonina e arginina digestíveis do milho e subprodutos, por meio das equações de predição, em função da composição química dos alimentos (expressos com base na matéria seca) $)^{1}$

Table 10 - Estimation of digestible lysine, methionine, methionine plus cystine (Met+Cys), threonine and arginine contents of the corn and corn byproducts by the prediction equations, based on the chemical composition (data based in dry matter)

\begin{tabular}{|c|c|c|c|c|c|c|c|c|c|c|}
\hline \multirow[t]{2}{*}{$\begin{array}{l}\text { Alimento } \\
\text { Feedstuff }\end{array}$} & \multicolumn{2}{|c|}{$\begin{array}{l}\text { Lisina } \\
\text { Lysine }\end{array}$} & \multicolumn{2}{|c|}{$\begin{array}{l}\text { Metionina } \\
\text { Methionine }\end{array}$} & \multicolumn{2}{|c|}{$\begin{array}{c}\text { MET + CIS } \\
M e t+C y s\end{array}$} & \multicolumn{2}{|c|}{$\begin{array}{l}\text { Treonina } \\
\text { Threonine }\end{array}$} & \multicolumn{2}{|c|}{$\begin{array}{l}\text { Arginina } \\
\text { Arginine }\end{array}$} \\
\hline & $\mathrm{Obs}^{2}$ & $\mathrm{Est}^{3}$ & Obs & Est & Obs & Est & Obs & Est & Obs & Est \\
\hline Milho 1 & 0,25 & 0,35 & 0,20 & 0,20 & 0,46 & 0,40 & 0,33 & 0,34 & 0,40 & 0,54 \\
\hline $\begin{array}{l}\text { Corn 1 } \\
\text { Milho } 2 \\
\text { Corn } 2\end{array}$ & 0,27 & 0,33 & 0,22 & 0,16 & 0,44 & 0,34 & 0,28 & 0,28 & 0,43 & 0,50 \\
\hline $\begin{array}{l}\text { Milho QPM } \\
\text { Quality protein maize }\end{array}$ & 0,36 & 0,33 & 0,14 & 0,15 & 0,28 & 0,32 & 0,27 & 0,26 & 0,47 & 0,48 \\
\hline $\begin{array}{l}\text { Milho pré-cozido } \\
\text { Pre-cooked corn }\end{array}$ & 0,25 & 0,34 & 0,19 & 0,17 & 0,36 & 0,35 & 0,29 & 0,28 & 0,38 & 0,50 \\
\hline $\begin{array}{l}\text { Farelo de glúten } 60 \\
\text { Corn gluten feed }\end{array}$ & 0,99 & 0,96 & 1,35 & 1,32 & 2,23 & 2,17 & 2,15 & 2,11 & 1,91 & 1,84 \\
\hline $\begin{array}{l}\text { Farelo de glúten } 21 \\
\text { Corn gluten meal }\end{array}$ & 0,41 & 0,53 & 0,36 & 0,54 & 0,75 & 0,93 & 0,75 & 0,87 & 0,69 & 0,93 \\
\hline $\begin{array}{l}\text { Gérmen de milho (GM) } \\
\text { Corn germ - CG }\end{array}$ & 0,34 & 0,34 & 0,19 & 0,18 & 0,37 & 0,36 & 0,32 & 0,30 & 0,57 & 0,51 \\
\hline $\begin{array}{l}\text { Gérmen de milho fino } \\
\text { Fine } C G\end{array}$ & 0,53 & 0,35 & 0,21 & 0,19 & 0,42 & 0,38 & 0,35 & 0,32 & 0,81 & 0,53 \\
\hline $\begin{array}{l}\text { GM desengordurado } \\
\text { Free-fat } C G\end{array}$ & 0,51 & 0,36 & 0,20 & 0,22 & 0,38 & 0,43 & 0,37 & 0,36 & 0,73 & 0,56 \\
\hline Médias das estimativas & 0,43 & 0,43 & 0,34 & 0,35 & 0,63 & 0,63 & 0,57 & 0,57 & 0,71 & 0,71 \\
\hline $\begin{array}{l}\text { Médias } \\
\text { Means }^{4}\end{array}$ & \multicolumn{2}{|c|}{0,01059} & \multicolumn{2}{|c|}{0,00399} & \multicolumn{2}{|c|}{0,00601} & \multicolumn{2}{|c|}{0,00198} & \multicolumn{2}{|c|}{0,0234} \\
\hline
\end{tabular}

1 Lisina = 0,23518 + 0,01067PB $\left(R^{2}=0,78\right) ;$ Metionina = -0,02198 + 0,01951PB $\left(R^{2}=0,97\right) ;$ Metionina + cistina = 0,04767 + 0,03143PB $\left(R^{2}=0,98\right) ;$ Treonina $=-0,01738+0,03156 \mathrm{~PB}\left(\mathrm{R}^{2}=0,99\right)$; Arginina $=0,28013+0,02318 \mathrm{~PB}\left(\mathrm{R}^{2}=0,88\right)$

2 Conteúdo de aminoácidos digestíveis verdadeiros obtidos por intermédio dos coeficientes de digestibilidade determinados in vivo com galos adultos cecectomizados (Digestible amino acids content obtained by the digestibility coefficients determined in vivo with cecectomized adult cockerels).

3 Valores estimados pelas equações de predição (Estimated values by the prediction equations).

${ }^{4}$ Médias da soma do quadrado dos desvios (Square deviation sum means).

metionina digestível variou em $2,94 \%$. No entanto, quando se avaliam isoladamente os alimentos, observa-se que a lisina e arginina totais e digestíveis mostraram uma tendência de serem, de certa forma, superestimadas para o milho e subestimadas para as amostras de gérmen de milho fino e desengordurado, o que, possivelmente, está associado aos menores valores de $\mathrm{R}^{2}$ encontrados no ajuste das equações para estes dois aminoácidos. Apesar destas observações, as equações foram, de maneira geral, boas em predizer o conteúdo de aminoácidos totais ou digestíveis dos alimentos estudados, considerando que as estimativas foram obtidas por meio das equações que continham apenas a PB como variável, já que apresentaram alta correlação positiva com os aminoácidos em questão e, conseqüentemente, menores $\mathrm{R}^{2}$, quando comparado àquelas com mais variáveis que, certamente, farão melhores predições.

\section{Conclusões}

Os coeficientes médios de digestibilidade dos aminoácidos (essenciais e não- essenciais) das amostras de milho 1, 2, QPM e pré-cozido, farelos de glúten 60 e 21, gérmen de milho, gérmens de milho fino e desengordurado e dos milhetos 1 e 2 foram 92,02 e 90,$69 ; 88,62$ e 87,$33 ; 88,40$ e 85,$75 ; 90,20$ e 88,$99 ; 95,04$ e 94,$84 ; 82,11$ e 79,$10 ; 91,84$ e 91,30 ; 92,56 e 91,$59 ; 87,92$ e 86,$18 ; 91,04$ e 88,$70 ; 93,55$ e $93,79 \%$, respectivamente; alimentos com maior teor de fibra, como o farelo de glúten 21, apresentam menores coeficientes de digestibilidade dos aminoácidos; o milheto apresentou aminoácidos de alta digestibilidade, podendo ser um alimento alternativo ao milho nas formulações; as equações contendo a variável PB fizeram boas estimativas do conteúdo de aminoácidos totais e digestíveis dos alimentos, 
sendo: Lisina total $=0,26488+0,01198 \mathrm{~PB} ;$ Metionina total $=-0,01315+0,02031 \mathrm{~PB} ;$ Metionina + cistina total $=0,07769+0,03448 \mathrm{~PB} ;$ Treonina total $=0,05576$ $+0,03410 \mathrm{~PB}$ e Arginina total $=0,30805+0,02370 \mathrm{~PB}$ e Lisina digestível $=0,23518+0,01067 \mathrm{~PB}$; Metionina digestível $=-0,02198+0,0195 \mathrm{~PB} ;$ Metionina + cistina digestível $=0,04767+0,03143 \mathrm{~PB}$; Treonina digestível $=$ $-0,01738+0,03156 \mathrm{~PB}$ e Arginina digestível $=0,28013$ $+0,02318 \mathrm{~PB}$.

\section{Referências Bibiliográficas}

ADEOLA, O., ROGLER, J.C. 1994. Pearl millet in diets of white pekin ducks. Poult. Sci., 73(2):425-435.

ALBINO, L.T.F., ROSTAGNO, H.S., SANT'ANNA, R. et al. 1992. Determinação dos valores de aminoácidos metabolizáveis e proteína digestível de alimentos para aves. R. Soc. Bras. Zootec., 21(6):1059-1068.

ALBINO, L.F.T., SILVA, M.A. Tópicos Avançados em Exigências Nutricionais para Frangos de Corte. In: CONGRESSO INTERNACIONAL, 1; CONGRESSO NACIONAL, 6 e CONGRESSO ESTADUAL, 14. Porto Alegre, RS, 1996. Anais... Porto Alegre: PUCRS - Faculdade de Zootecnia, Veterinária e Agronomia, 1996, p.59-64.

BATH, D., DUNBAR, J., KING, J. et al. 1999. Byproducts and unusual feedstuffs. Feedstuffs, 71(31).

BELLAVER, C. Metodologias para determinação do valor das proteínas e utilização de valores disponíveis nas dietas de não ruminantes. In: SIMPÓSIO INTERNACIONAL DE NÃORUMINANTES - REUNIÃO ANUAL DA SOCIEDADE BRASILEIRA DE ZOOTECNIA, 31, Maringá, 1994. Anais... Maringá: SBZ, 1994. p.1-23.

BELLAVER, C., PARSONS, C., EASTER, R.A. 1998. Estimativas da digestibilidade verdadeira de ingredientes de alimentos, obtida com galos cecotomizados em alimentação forçada. Pesq. Agropec. Bras., 33(5):731-736.

BERTECHINI, A.G., FASSANI, E.J., FIALHO, E.T. 1999. Utilização do milho QPM (quality protein maize) para aves. Ciência e Agrotec., 23(2):434-440.

COON, C. N. Optimizing ingredient utilization through a better understanding of amino acid bioavailability. In: TECHNICAL SYMPOSIA, 1991, Aruba. Proceedings... Aruba: NOVUS INTERNATIONAL, 1991. p.11-40.

DALE, N. Ingredient analysis table: 1999 edition. Feedstuffs, 71(31):24-31.

DEGUSSA, A.G. 1993. Digestble amino acids in feedstuffs for poultry. Frankfurt. $18 \mathrm{p}$.

EMBRAPA - CNPSA. 1991. Tabela de composição química e valores energéticos de alimentos para suínos e aves. 3.ed. Concórdia: CNPSA. 97p. (Doc., n.19).

FISCHER JR, A.A. Valores de energia metabolizável e de aminoácidos digestiveis de alguns alimentos para aves. Viçosa, UFV, 1997. 55p. Dissertação (Mestrado em Zootecnia) - Universidade Federal de Viçosa, 1997.

FISCHER JR, A.A., ALBINO, L.F.T., ROSTAGNO, H.S. et al. 1998. Determinação dos coeficientes de digestibilidade e dos valores de aminoácidos digestíveis de diferentes alimentos para aves. R. Soc. Bras. Zootec., 27(2):307-313.

JOHNSON, R. J. 1992. Principles, problems and application of amino acid digestibility in poutry. World's P. Sci. J., 48(3):232-246.
LAWRENCE, B.V., ADEOLA, O., ROGLER, J.C. 1995. Nutrient digestibility and growth performance of pigs fed pearl millet as a replacement for corn. J. of An. Sci., 73(7):20262032.

LESSON, S., YERSIN, A., VOLKER, L. 19993. Nutritive value of the 1992 corn crop. J. Appl. Poultry Res, 2:208-213.

NATIONAL RESEARCH COUNCIL - NRC. 1998. Nutrient requirements of swine. 3.ed. Washington: National Academy Press. 189 p.

NATIONAL RESEARCH COUNCIL - NRC. 1994. Nutrient requirements of poultry. 9.ed. Washington: National Academy Press. $155 \mathrm{p}$.

NUNES, R.V. Valores energéticos e de aminoácidos digestiveis da grão de trigo e seus subprodutos para aves. Viçosa, MG: UFV, 1999. 71p. Dissertação (Mestrado em Zootecnia) Universidade Federal de Viçosa, 1999.

PARSONS, C.M. Digestible amino acids for poultry and swine. 1996. Anim. Feed Sci. Tecn., 59(1-3):147-153.

PARSONS, C.M. 1984. Influence of caecectomy and source of dietary fibre or starch on excretion of endogenous amino acids by laying hens. Br. J. Nut., 51(3):541-548.

PUPA, J.M.R., LEÃO, M.I., CARVALHO, A.U. et al. 1998. Cecectomia em galos sob anestesia local e incisão abdominal. Arq. Bras. Med. Vet. Zootec, 50(5):531-535.

PUPA, J.M.R. Rações para frangos de corte formuladas com valores de aminoácidos digestiveis verdadeiros, determinados com galos cecectomizados. Viçosa, MG: UFV, 1995. 63p. Dissertação (Mestrado em Zootecnia) - Universidade Federal de Viçosa, 1995.

RHÔNE POULENC ANIMAL NUTRITION. 1993. Rhodimet ${ }^{\mathrm{TM}}$ Nut. Guide. 2.ed. 55p.

ROSTAGNO, H.S. Valores de composição de alimentos e exigências nutricionais utilizados na formulação de rações para aves. In: REUNIÃO ANUAL DA SOCIEDADE BRASILEIRADE ZOOTECNIA, 27., Piracicaba, 1990. Anais... Piracicaba: FEALQ, 1990. p.11-30.

ROSTAGNO, H.S., FEATHERSTON, W.R. 1977. Estudos de métodos para determinar disponibilidade de aminoácidos em pintos. R. Soc. Bras. Zootec., 6(1):64-76.

ROSTAGNO, H.S., PUPA, J.M.R., PACK, M. 1995. Diet Formulation for broilers based on total versus digestible amino acids. J. Appl. Poult. Res., 4:293-299.

ROSTAGNO, H.S., SILVA, D.J., COSTA, P.M.A. et al. 1983. Composição de alimentos e exigências nutricionais de aves e suínos (tabelas brasileiras). Viçosa: UFV. 59p.

ROSTAGNO, H.S., NASCIMENTO, A.H., ALBINO, L.F.T. Aminoácidos totais e digestíveis para aves. In: SIMPÓSIO INTERNACIONAL SOBRE NUTRIÇÃO DE AVES, Campinas, SP, 1999. Anais... Campinas: FACTA, 1999. p.65-83.

SIBBALD, I. R. 1979. A bioassay for available amino acids and true metabolizable energy in feedstuffs. Poult. Sci., 58(3):668-673.

SILVA, D.J. 1990. Análise de alimentos (métodos químicos e biológicos). 2.ed. Viçosa: UFV. 165p.

SMITH, R.L., JENSEN, L.S., HOVELAND, C.S. et al. 1989. Use of pearl millet, sorghum, and triticale grain in broiler diets. J. Prod. Agric., 2(1):78-82.

UNIVERSIDADE FEDERAL DE VIÇOSA - UFV. 1992. SAEG - Sistema de análises estatísticas e genéticas. Versão 5.0. Viçosa, MG: 59p. (Manual do usuário).

Rev. bras. zootec., 30(6S):2046-2058, 2001

Recebido em: 23/03/01 Aceito em: 02/07/01 